\title{
Mode of life and hydrostatic stability of orthoconic ectocochleate cephalopods: Hydrodynamic analyses of restoring moments from 3D printed, neutrally buoyant models
}

\author{
David J. Peterman, Charles N. Ciampaglio, Ryan C. Shell, and Margaret M. Yacobucci \\ Acta Palaeontologica Polonica 64 (3), 2019: 441-460 doi:https://doi.org/10.4202/app.00595.2019
}

Theoretical 3D models were digitally reconstructed from a phragmocone section of Baculites compressus in order to investigate the hydrostatic properties of the orthoconic morphotype. These virtual models all had the capacity for neutral buoyancy (or nearly so) and were highly stable with vertical syn vivo orientations. Body chamber lengths exceeding approximately $40 \%$ of the shell length cause buoyancy to become negative with the given modeled proportions. The distribution of cameral liquid within the phragmocone does not change orientation and only slightly influences hydrostatic stability. The mass of cameral liquid required to completely reduce stability, permitting a non-vertical static orientation, would cause the living cephalopod to become negatively buoyant. A concave dorsum does not significantly change the mass distribution and results in a $5^{\circ}$ dorsal rotation of the aperture from vertical. The restoring moments acting to return neutrally buoyant objects to their equilibrium position were investigated using 3D-printed models of Nautilus pompilius and Baculites compressus with theoretically equal masses and hydrostatic stabilities to their virtual counterparts. The $N$. pompilius behaved as an underdamped harmonic oscillator during restoration due to its low hydrostatic stability and drag relative to the $B$. compressus model. In contrast, the $B$. compressus model more quickly returns to its equilibrium position without oscillating (overdamped system). The thrust required to overcome such a large restoring moment was explored using several extant cephalopod analogues. Significant angles of displacement were only achieved with coleoid-like thrusts, which were unrealistically high despite the probable similarities in their locomotor design. These maximum bursts of thrust may have been too energetically expensive and would preclude an unusual form of locomotion in a non-vertical orientation. These results suggest baculitids and other orthocones with similar hydrostatic stabilities probably lived a nektic to quasiplanktic mode of life with a primarily vertical orientation and mobility.

Key words: Cephalopoda, Ammonoidea, Baculite, 3D imaging, 3D printing, hydrostatics, buoyancy, Cretaceous.

David J. Peterman [peterman.10@wright.edu] and Ryan C. Shell [shell.24@wright.edu 
N. Ciampaglio [chuck.ciampaglio@wright.edu], Department of Science and Mathematics, Wright State University Lake Campus, Dwyer Hall 219, 7600 Lake Campus Dr., Celina, OH 45822, USA. Margaret M. Yacobucci [mmyacob@bgsu.edu], Department of Geology, Bowling Green State University, 190 Overman Hall, Bowling Green, Ohio 43403, USA.

This is an open-access article distributed under the terms of the Creative Commons Attribution License (for details please see creativecommons.org), which permits unrestricted use, distribution, and reproduction in any medium, provided the original author and source are credited.

FoF Full text $(1,144.5 \mathrm{kB})$ 